\title{
An Exploration of Blockchain-based Traceability in Food Supply Chains: On the Benefits of Distributed Digital Records from Farm to Fork
}

\section{Mika Westerlund, Soham Nene, Seppo Leminen, Mervi Rajahonka}

\author{
"Companies are increasingly taking responsibility for the safety of the food \\ they sell, rather than risk their brand on a large recall." \\ Andy Kennedy \\ Co-founder of FoodLogiQ
}

\begin{abstract}
There are growing internal and external pressures for traceability in food supply chains due to food scandals. Traceability refers to tracking food from the consumer back to the farm and vice versa for quality control and management. However, many traceability solutions have failed to meet the needs of supply chain stakeholders. Blockchain is a novel distributed database technology that could solve some issues of traditional traceability systems, such as cost of adoption and vulnerabilities to hacking and data tampering. This study aims to gain insights on the benefits of applying blockchain technology for traceability in food supply chains through literature review and an investigation of five companies that are experimenting with blockchain-based food traceability. Our findings suggest that, upon implementation and contribution by all supply chain participants, blockchain-based traceability can provide costsavings, reduced response time to food scandals and food-borne illness outbreaks, improved security and accuracy, better compliance with government regulations, and thus increase consumer trust.
\end{abstract}

\section{Introduction}

In recent years, various food scandals have damaged consumer trust in the food industry across the world (Sarpong, 2014; Garaus \& Treiblmaier, 2021). In 2011, China witnessed a massive pork mislabeling scandal along with food fraud, which led to recalling donkey meat products that included fox meat (Kamath, 2018). In 2013, several meat suppliers in Europe replaced lamb and beef with horsemeat, which affected 4.5 million processed products, equaling 1,000 tons of food (Kamath, 2018). In 2017, papayas in the US market were linked to a multi-state outbreak of Salmonella (Kamath, 2018). Meanwhile four million Canadians are affected by domestically acquired foodborne illnesses each year, which resulted from food contamination (Astill et al., 2019).

Both food companies and consumers would benefit from faster response times to food scandals and outbreaks of foodborne illnesses (Aung \& Chang, 2014; Astill et al., 2019). Typically, food incidents are slow in being handled due to low transparency and inefficient batch sorting, which leads to an inability to trace food items in the supply chain (Sarpong, 2014; He et al., 2018). Further, the complexity and dynamics of modern food supply chains, along with large distances between supply chain entities, make it an ongoing challenge to ensure food safety and quality (He et al., 2018; Behnke \& Jansson, 2020). Hence, traceability has become paramount in global food supply chains because consumers expect higher levels of reliability and safety (Casino et al., 2019; Behnke \& Janssen, 2020; Tayal et al., 2021).

"Traceability" refers to the ability to track an item in the supply chain from producer to user, enabled by rapid access to relevant and reliable information (Bhatt et al., 


\title{
An Exploration of Blockchain-based Traceability in Food Supply Chains: On the Benefits of Distributed Digital Records from Farm to Fork
}

\author{
Mika Westerlund, Soham Nene, Seppo Leminen, Mervi Rajahonka
}

2013; Xiong et al., 2020). It helps to ensure food safety and quality, as food is a perishable product and foodborne illnesses can originate from mishandling anywhere in a supply chain (Yon \& Woo, 2018). That said, retailers are often inundated with data, while suppliers are reluctant to waste valuable transport time completing checklists and audits (Sarpong, 2014). Hence, automated data gathering and storage might be preferable to human data entry practices, and a distributed system solution with the option of data mining could be a more feasible solution than relying on a single centralized database (Bhatt et al., 2013; Bumblauskas et al., 2020; van Hilten et al., 2020).

As a meta-technology, blockchain allows for improved traceability in food supply chains (Kramer et al., 2021). Being built on a decentralized and distributed database (Vu et al., 2021), blockchain enhances transparency, accountability, trust, and traceability in supply chains (Kim \& Laskowski, 2017; Gurtu \& Johny, 2019; Behnke \& Jansson, 2020). Kshetri (2018) also argues that it contributes to cost, quality, speed, dependability, risk reduction, sustainability, and flexibility goals. Nonetheless, the adoption of blockchain technology in food supply chain management is still in its infancy, thus allowing us only a limited understanding of its potential (Treiblmaier, 2018; Müßigmann et al., 2020; Lim et al., 2021). More research is needed on the benefits and challenges of blockchain-based traceability in food supply chains.

This study aims to provide insights mainly about the benefits of blockchain-based traceability in food supply chains. In so doing, the article first reviews recent literature on blockchain technology and traceability in supply chain management, and then discusses five industry cases on blockchain-based traceability in food supply chains. The insights derived from the cases contribute to our extant body of knowledge on the application of blockchain in the supply chain management field, by outlining how blockchain helps to improve food product traceability. The article concludes with implications for practice and suggestions about potential future research avenues.

\section{Literature Review}

The impacts of blockchain on supply chain management Blockchains use a common shared ledger that records transactions made by users (Mansfield-Devine, 2017; Casado-Vara et al., 2018; Kamilaris et al., 2019). A sequential list of timestamped records gets spread among a network of users whose machines are all running the blockchain protocol, in order to be validated by the nodes (Mansfield-Devine, 2017; Kamilaris et al., 2019; Wang et al., 2019). "Blocks" form a linked chain of hashed information, and each block must refer to the preceding block to be valid (Tapscott \& Tapscott, 2017). This distributed approach is more secure than earlier technology allowed because it uses cryptography (Casado-Vara et al., 2018; Chang \& Chen, 2020; Wang et al., 2020), and more trustworthy because the structure permanently time-stamps and stores the information in blocks, preventing anyone from altering the ledger (Lemieux, 2016; Ying et al., 2018; Behnke \& Janssen, 2020).

Indeed, key characteristics of blockchain-based systems include security, reliability, transparency, and immutability (Wang et al., 2020). In a blockchain system, no central authority controls or maintains the network. Instead, the network is maintained by the participating nodes, while updating information in the database requires the consensus of ledger community participants (Ying et al., 2018; Pournader et al., 2020).

Conversely, when using a centralized database, someone must act as a trusted authority (MansfieldDevine, 2017). This central authority actor, however, for a variety of reasons, may turn out to have a somewhat or very limited view of an entire supply chain, which thus hinders collaboration, delays information processing, and increases the risk of data corruption, as data flows through intermediaries (Apte \& Petrovsky, 2016; Mukri, 2018). Thus, a traditional pre- or nonblockchain system is more vulnerable to corruption, hacking, data leaking, contractual disputes, tampering, and fraud (Azzi et al., 2019; Min, 2019; Chen et al., 2021). This makes blockchains for supply chain management a proverbial "game changer", meaning a foundational technological disruption to both global and local current supply chain systems.

Although the potential of distributed ledger technologies extends beyond cryptocurrencies and peer-to-peer (P2P) payment systems (Iansati \& Lakhani, 2017; Grecuccio et al., 2020; Teodorescu \& Korchagina, 2021), the expected variety of industrial blockchain applications still remains to be seen (Casino et al., 2019; Bumblauskas et al., 2020; Chang \& Chen, 2020). The original blockchain design with Bitcoin was as a "permissionless" system open for anyone to use P2P. 


\section{An Exploration of Blockchain-based Traceability in Food Supply Chains: On the Benefits of Distributed Digital Records from Farm to Fork}

\section{Mika Westerlund, Soham Nene, Seppo Leminen, Mervi Rajahonka}

However, industrial applications tend to use "permissioned" systems that allow authorizing only selected users to join a network and controlling user permissions for safety or necessary business privacy purposes (Behnke \& Janssen, 2020). Permissioned blockchain systems in the business-to-business context build on business-technology frameworks like Hyperledger (Behnke \& Janssen, 2020), which enable permissioned users to have duplicated transactional records, as well as permission access to monitor the movement and progress of supply chain flows (Chang \& Chen, 2020).

The transparency of blockchain systems can help establish the authenticity of transactions (MansfieldDevine, 2017), while removing intermediaries from the old systems can enable transactions to become faster between supply chain actors (van Hilten et al., 2020). In this vein, distributed ledger technology allows supply chain partners to reduce or eliminate transaction costs. It may also allow them to use untrusted external resources, as easily as they currently use trusted internal resources (Tapscott \& Tapscott, 2017). Further, blockchain technology improves supply chain dependability by exerting increased pressure on supply chain partners to be more responsible and accountable for their actions (Kshetri, 2018). As a result, both the improved connectivity among supply chain partners and the increased visibility of information flows can offer consumers more detailed information about the origin of products (Casado-Vara et al., 2018). In food supply chains, knowing the origin of products means improved food safety (Casino et al., 2019).

\section{The importance of traceability in food supply chains}

The growing public attention to food quality and safety have led to developing food traceability systems (Dabbene et al., 2014; Chen, 2015; Astill et al., 2019). "Traceability" signifies the ability to track a product and its history through a supply chain from harvest through transport, storage, processing, distribution, and retail (Moe, 1998; Kamilaris et al., 2019). This requires significant information sharing about product history, specification, and location, among a network of others (Kumar et al., 2017). Of note, traceability can be classified according to the direction in which information is recalled in a food chain (Aung \& Chang, 2014). Similarly but distinctly, "tracking" refers to the ability to follow-up the downstream path of a product along a supply chain, while "tracing" refers to the ability to determine the origin of a product and its ingredients, using records held upstream in the supply chain (Dabbene et al., 2014; Behnke \& Janssen, 2020).

Traceability necessitates the engagement of stakeholders along an entire food supply chain (Dabbene et al., 2014). Since traceability systems can yield huge volumes of data, automated data collection, storage, and accessibility become critical (Chen, 2015). According to Dabbene et al. (2014), such automation uses machine-readable optical labels (QR codes) and radio frequency identification devices (RFID) to enhance the precision and reliability of identifying traced units. Tracing focuses on "batches" (products with the same "best before" date and batch number), "trade units" (boxes of products with the same batch numbers, sent along a supply chain), or "truck units" (pallets of products with different batch numbers, for distribution or storage purposes) (Behnke \& Janssen, 2020).

With reliable information, traceability can improve food safety through timely identification of food sources and by providing better information about the causes of potential food contamination (Astill et al., 2019; Lin et al., 2021). Ene (2013) noted that the objectives of food supply chain traceability include: 1) contributing to food safety by enabling the identification of outbreak or hazard sources, managing safety alerts, and withdrawing contaminated or dangerous products; 2) providing reliable information to users by guaranteeing product authenticity, and that certain production practices have been followed; and 3) improving overall product quality and processes by identifying sources of noncompliance, while enhancing product flows and stock management.

According to Opara (2003), six key elements of traceability constitute the food supply chain traceability system:

1. Product traceability: physical location of a product at any stage in the supply chain, inventory management, product recall, type of product traceability, and type of food to be traced.

2. Process traceability: type and sequence of activities affecting the product (cause, location, time; chemical, physical, environmental, and atmospheric factors), compliance standards and regulations with governmental entities, and collaboration among food supply chain entities. 


\section{An Exploration of Blockchain-based Traceability in Food Supply Chains: On the Benefits of Distributed Digital Records from Farm to Fork}

\section{Mika Westerlund, Soham Nene, Seppo Leminen, Mervi Rajahonka}

3. Genetic traceability: genetic product constitution, type and origin of ingredients, information on planting materials (seed, stem cuttings, tuber) to create the original product.

4. Input traceability: type and origin of inputs such as fertilizers, chemical sprays, livestock, feed, additives, and chemicals for preservation.

\section{Disease and pest traceability: involving the} epidemiology of pests, bacteria, viruses, and emerging pathogens, which may contaminate food.

\section{Measurement traceability: measurement standards,} length, depth, precision to trace, quality control, and type of traceability.

In general, supply chain partners have both internal and external traceability requirements. Internal traceability includes, for example, sharing logistic data, inventory data, contracts, prices, and organic product certification links, while external traceability refers to, for example, providing food origin information and farmer data to consumers (Yon \& Woo, 2018; van Hilten et al., 2020; Xiong et al., 2020). Thus, we see consumers calling for food safety, while farmers wish traceability systems that can aid them in crop management that increases their profits (Xiong et al., 2020; Chen et al., 2021). An increasing need therefore exists to provide traceability from "farm to fork", whereas the current costs of putting traceability systems into place are a major barrier for most supply chain actors (Aung \& Chang, 2014; Casino et al., 2019). That said, if the benefits of food traceability come to be seen as outweighing the costs involved, then blockchain-based systems may indeed be a gamechanger in this respect.

\section{Blockchain-based traceability in food supply chains}

According to Paliwal et al. (2020), improved traceability is one of the key benefits of applying distributed ledger technology. Other benefits of adopting blockchainbased food traceability involve data interoperability, cost reduction, transparency, auditability, integrity and authenticity, as well as improved data accuracy, data management, and prediction through data analytics in food logistics (Casino et al., 2019; Pournader et al., 2020). Further, blockchain-enabled food traceability allows for improved cybersecurity and reduced food fraud, by using strong cryptography (Wang et al., 2020) and by identifying counterfeiting, dilatation, and adulteration, in support of better food security and safety (Etemadi et al., 2021; Garaus \& Treiblmaier, 2021; Tayal et al., 2021).

Within a blockchain system, information is tied to each individual product, creating a digital record that proves its provenance, compliance, authenticity, and quality (Bumblauskas et al., 2020). Blockchain systems not only carry information on each transaction, but also associated metadata (origin, contracts, process steps, environmental variations, microbial records) that can be used to connect items across the entire supply chain (Pearson et al., 2019; Wang et al., 2020). Some of the data are collected via sensor networks tracking location, time, temperature, and humidity levels, and are reported on the blockchain in real-time (Grecuccio et al., 2020). Traceability based on such real-time, reliable, and accurate data can increase accountability in a food supply chain, improve shelf life, help prevent food loss, and increase consumer trust in the brand (Kayikci et al., 2020; Shahbazi \& Byun, 2021).

\section{Methodology}

We selected five companies that have recently experimented or are experimenting with blockchainbased food traceability as case studies to further investigate the benefits of using blockchain technology for traceability in food supply chains. Chang and Chen (2020) argue that the case study method is a highly informative approach to study blockchains in supply chain management. Our case study data were collected in 2018, and include Walmart, Provenance, Carrefour, Foodchain, and Ripe.io. No specific criteria for choosing the cases were used, besides that they needed to address a blockchain-enabled food supply chain management pilot. Data on the cases were found in scholarly and practitioner literatures on innovation management and food business, and we also used online sources such as industry magazines, blogs, news articles, and corporate websites to collect further information.

We utilized a content analysis method for our data collected from the five cases. We examined and analyzed the case data based on traceability elements that were inferred from the literature review (Opara, 2003). Specifically, we looked for information about how the companies involved in each case applied blockchain applications for solving their food supply chain traceability problems according to common traceability elements. Then, we performed a descriptive analysis, which included creating brief case descriptions, and a table that reflected the context of the blockchain 


\title{
An Exploration of Blockchain-based Traceability in Food Supply Chains: On the Benefits of Distributed Digital Records from Farm to Fork
}

\author{
Mika Westerlund, Soham Nene, Seppo Leminen, Mervi Rajahonka
}

experiments and summarized key insights from data. These insights highlight how the case companies applied blockchain technology to solve food supply chain traceability problems, as well as what the perceived or pursued benefits of establishing a blockchain-based traceability system were.

\section{Findings}

The following sections provide brief case descriptions to understand the context of each case. Thereafter, we summarize key insights from the cases in a table.

\section{Case 1: Walmart - pork and mango pilots with IBM}

In 2016, Walmart launched two pilots using IBM's Hyperledger-based blockchain solution to trace the origin of sliced mangoes sold in North America and pork sold in China. Walmart chose IBM's solution as it was not recreating an existing supply chain, but rather leveraging emerging technologies to enhance supply chain traceability. Walmart had to establish trust through its traceability system due to various recent outbreaks of foodborne illnesses, while the resulting traceability included numerous stages from food production through food consumption. The length, depth, and precision of the food supply chain included farm and slaughterhouse tracking, and store tracking with Walmart's distribution center.

Blockchain technology helped Walmart create greater transparency, veracity, and trust in its food information, so that its supply chain partners could act immediately if a problem arose. Also, they found that cooperation with government entities was crucial. The supply chain entities were able to record, trace, and verify the authenticity and quality of their products throughout the product lifecycle, across multiple different authorities. Audits, identification numbers, and safetyprotocols were logged in real-time and stored as ecertificates. Notably, Walmart's blockchain enabled tracing at the item level, not just batch level. This allowed officials to determine the origin of a specific mango in just two seconds. Addressing several vulnerabilities in the food supply chain, Walmart's pilots went beyond technology to gain people's trust and confidence in food.

\section{Case 2: Provenance - tracking tuna on the blockchain}

Provenance is a UK-based firm behind a digital platform that enables retailers to bring integrity and transparency to their supply chains. Their goals are to track tuna caught by fishermen with verified and sustainable claims, including traceability and compliance to standards at the origin and along the chain, as well as preventing the "double spend" of product certificates and identification tags. Provenance chose to first understand the key supply chain problems in tuna fishing and then assess the technology opportunities in Indonesia, the largest tuna producing country in Southeast Asia.

Some of the problems were human rights abuses, overfishing, fraud, and illegal, unreported, and unregulated fishing. The firm made use of a hybrid blockchain solution, allowing them to trace the source of tuna in minutes, rather than days or weeks as had been usual previously. In the pilot, fishermen sent SMS messages to register their catch on the Provenance blockchain. Information on the origin and supply chain journey of the fish could be accessed and verified by consumers using their smartphones. In this vein, Provenance could provide a robust proof of compliance to standards by government authorities at the origin and along the entire food supply chain.

\section{Case 3: Carrefour - tracing of chickens, cheese, milk, oranges, and salmon}

Carrefour is a European retailer experimenting with food supply chain traceability through blockchain technology. The pilot involved IBM to create a food trust platform aimed at providing better transparency, traceability, and efficiency in food supply chains from farm to fork. Carrefour aimed to track free-range chickens, eggs, cheese, milk, oranges, tomatoes, salmon and ground beef steak, among others, with an objective of implementing a global food traceability standard across all links of its supply chain.

Carrefour's solution is based on Ethereum. It helped them to accurately record events along the supply, processing, packaging, and distribution chain. However, for tomatoes and eggs, they began experimenting with Hyperledger Fabric, because it includes the concept of information "channels", which are equivalent to having multiple separate blockchains at the same time. In other words, the firm can have one channel per product line. Carrefour's perception is that this facilitates the multiplication of different blockchains on a single common core. They consider this as a major enabler of industrializing blockchains. 


\title{
An Exploration of Blockchain-based Traceability in Food Supply Chains: On the Benefits of Distributed Digital Records from Farm to Fork
}

\author{
Mika Westerlund, Soham Nene, Seppo Leminen, Mervi Rajahonka
}

Case 4: Foodchain - creating stories from farm to fork

Foodchain S.p.A. is an Italian start-up company with a blockchain-based traceability service. The company strives to use blockchain technology to gain a competitive advantage in food supply chain transparency and traceability. The first phase was identifying and registering raw materials and producers in the blockchain. Thereafter, each food item was recorded on a blockchain using a "smart label", such as a unique QR code. The entire process was monitored, while quality control of the product was tracked in realtime and shareable between all stakeholders of the food supply chain through computer or smartphone.

Given the immutability of data stored on a blockchain ledger, Foodchain S.p.A. believes that it will help food brands to increase trust and loyalty among their customers. In other words, the company's QR codes allow consumers to access the full and immutable story of a food product and learn about all the steps made by the product before landing on their table. Thus, Foodchain enables the monitoring of the entire food supply chain, which aids in improving food quality control and traceability. Their blockchain implementation is private and permissioned, built on Ethereum, but the company has also launched its own public, permissionless blockchain infrastructure called Quadrans.

\section{Case 5: Ripe.io - The internet of tomatoes}

Ripe.io is a blockchain start-up company that showcases the value of distributed ledger technology in agriculture by collecting data throughout the entire food supply chain. Its pilot project was called the "Internet of Tomatoes", in which Ripe.io used a blockchain to compile a wealth of data from the farm and apply it to growing better tomatoes. It allowed data to be recorded of every single tomato produced by growers and share that information with the supply chain and consumers using blockchain technology. The objective of Ripe.io was to enable data transparency and traceability from farm to fork, by providing information on an individual tomato, including not only its origin with a farm and producer, but also its sweetness, texture, size, variety, nutritional value, how it was grown, and its ripening record.

For this purpose, Ripe.io collected data from each tomato produced by given growers, and shared the information with restaurant purchasers of tomatoes. Using blockchain technology allowed them to monitor every detail, such as temperature, humidity, and colour, and store the information digitally and securely. Ripe.io is attempting to create a system that can help firms save money through efficiency gains and remove adulterated food quickly and efficiently. Also, blockchain-based traceability allows retailers and authorities to trace and track every item in real time for more accurate monitoring and prediction of shipping and delivery.

\section{Summary of key insights from the cases}

Summing up the findings on blockchain-based traceability and its benefits in our five use cases, most value came from cost savings and reduced time for tracing food items through a food supply chain. Due to this, food data were digitally stored on a blockchain, and time to access information about a specific food product only took minutes, compared to weeks in previouslyused traditional traceability systems. The new system helped the companies studied in our cases to achieve cost savings, as well as time savings when solving food crises. Table 1 summarizes the key insights gathered from our use cases.

Another key benefit of operating with a shared distributed ledger is automatically achieving compliance with government standards. Prior to having a blockchain-based food traceability system, compliance with government requirements were often challenging due to disparate record-keeping and paperbased documents. Blockchain solved this problem by digitally and securely storing all compliance-based documents, thus eliminating the need for any paper documents. In the case of Walmart, it became easy for all supply chain entities to comply with government standards. Hence, the blockchain system helped firms to achieve better quality control over food, making it possible to trace the product from farm to fork, which in turn helped them to build increased trust with consumers as supply chain operations and management became more transparent.

Some traceability elements, such as product and process traceability appear to be common across the cases studied. For example, case companies attempted to trace individual items and promote enhanced coordination between supply chain entities to achieve better control over the supply chain. That said, only Carrefour covered all six traceability elements in its offering. Specifically, the category of "disease and pest traceability" was not seen consistently across the cases, as only Carrefour put special effort on it. In fact, 


\title{
An Exploration of Blockchain-based Traceability in Food Supply Chains: On the Benefits of Distributed Digital Records from Farm to Fork
}

\author{
Mika Westerlund, Soham Nene, Seppo Leminen, Mervi Rajahonka
}

Table 1. Summary of key insights

\begin{tabular}{|c|c|c|c|c|c|}
\hline Case & Insight 1 & Insight 2 & Insight 3 & Insight 4 & Insight 5 \\
\hline Walmart & $\begin{array}{l}\text { Hyperledger } \\
\text { Fabric and } \\
\text { modular } \\
\text { architecture } \\
\text { provide a robust } \\
\text { system for } \\
\text { traceability }\end{array}$ & $\begin{array}{l}\text { Blockchain } \\
\text { based } \\
\text { traceability can } \\
\text { solve the major } \\
\text { challenge of } \\
\text { compliance and } \\
\text { documentation }\end{array}$ & $\begin{array}{l}\text { Value of } \\
\text { traceability is } \\
\text { stronger if it } \\
\text { includes non- } \\
\text { perishable, } \\
\text { perishable, } \\
\text { and extra- } \\
\text { perishable } \\
\text { food products }\end{array}$ & $\begin{array}{l}\text { Top } \\
\text { management's } \\
\text { commitment is } \\
\text { crucial for the } \\
\text { adoption of } \\
\text { blockchain } \\
\text { technology }\end{array}$ & $\begin{array}{l}\text { Time to trace } \\
\text { food items is } \\
\text { significantly } \\
\text { reduced due } \\
\text { to the } \\
\text { blockchain } \\
\text { technology }\end{array}$ \\
\hline Provenance & $\begin{array}{l}\text { Hybrid } \\
\text { blockchain } \\
\text { provides a more } \\
\text { customized } \\
\text { implementation } \\
\text { of traceability }\end{array}$ & $\begin{array}{l}\text { Collaboration } \\
\text { between all } \\
\text { supply chain } \\
\text { entities helps to } \\
\text { gain more } \\
\text { control over the } \\
\text { supply chain }\end{array}$ & $\begin{array}{l}\text { Individual fish } \\
\text { traceability } \\
\text { helps } \\
\text { stakeholders } \\
\text { to achieve } \\
\text { individual } \\
\text { item tracking }\end{array}$ & $\begin{array}{l}\text { Blockchain } \\
\text { traceability } \\
\text { system is } \\
\text { integrated } \\
\text { downstream }\end{array}$ & $\begin{array}{l}\text { Integration } \\
\text { of blockchain } \\
\text { with RFID } \\
\text { technology } \\
\text { helps to } \\
\text { achieve the } \\
\text { best results }\end{array}$ \\
\hline Carrefour & $\begin{array}{l}\text { Compliance with } \\
\text { government } \\
\text { authorities is } \\
\text { essential }\end{array}$ & $\begin{array}{l}\text { Quality } \\
\text { monitoring is } \\
\text { easier with the } \\
\text { blockchain- } \\
\text { based system }\end{array}$ & $\begin{array}{l}\text { Information } \\
\text { about } \\
\text { adulterated } \\
\text { products can } \\
\text { be found } \\
\text { easily }\end{array}$ & $\begin{array}{l}\text { Product recall } \\
\text { in case of any } \\
\text { food crisis is } \\
\text { fast and } \\
\text { efficient }\end{array}$ & $\begin{array}{l}\text { Both forward } \\
\text { and } \\
\text { backward } \\
\text { traceability } \\
\text { are } \\
\text { important }\end{array}$ \\
\hline Foodchain & $\begin{array}{l}\text { Ethereum } \\
\text { platform and QR } \\
\text { codes help the } \\
\text { company with } \\
\text { efficient tracing }\end{array}$ & $\begin{array}{l}\text { Certification of } \\
\text { farms producing } \\
\text { coffee and } \\
\text { authentication } \\
\text { is necessary }\end{array}$ & $\begin{array}{l}\text { Traceability } \\
\text { g analysis } \\
\text { reports help } \\
\text { to improve } \\
\text { efficiency over } \\
\text { the supply } \\
\text { chain }\end{array}$ & $\begin{array}{l}\text { Blockchain- } \\
\text { enabled system } \\
\text { helps to gain } \\
\text { better } \\
\text { r transparency }\end{array}$ & $\begin{array}{l}\text { Enhanced } \\
\text { trust } \\
\text { throughout } \\
\text { the food } \\
\text { supply chain } \\
\text { is ensured }\end{array}$ \\
\hline Ripe.io & $\begin{array}{l}\text { Information to } \\
\text { tomato } \\
\text { producing } \\
\text { farmers is } \\
\text { important }\end{array}$ & $\begin{array}{l}\text { Data } \\
\text { transparency } \\
\text { and traceability } \\
\text { from farm to } \\
\text { fork is achieved }\end{array}$ & $\begin{array}{l}\text { Real-time } \\
\text { analysis and } \\
\text { status of } \\
\text { tomatoes can } \\
\text { be made }\end{array}$ & $\begin{array}{l}\text { Data } \\
\text { immutability } \\
\text { enables } \\
\text { credible details } \\
\text { of each } \\
\text { tomato's } \\
\text { growth }\end{array}$ & $\begin{array}{l}\text { Non- } \\
\text { tampering of } \\
\text { data can be } \\
\text { easily } \\
\text { ensured }\end{array}$ \\
\hline
\end{tabular}




\title{
An Exploration of Blockchain-based Traceability in Food Supply Chains: On the Benefits of Distributed Digital Records from Farm to Fork
}

\author{
Mika Westerlund, Soham Nene, Seppo Leminen, Mervi Rajahonka
}

Carrefour attempted to predict not only pathogens, but also allergens through the traceability system, which would help in disease and pest traceability. Allergens are not discussed in the previous literature as a traceability element.

The insights from our study also highlight that simply comprehending blockchain technology and how it creates ledger communities for supply chains is important because comprehension is the key to implementing an efficient DLT-based food traceability system. Understanding the advantages (and disadvantages) of public, private and hybrid blockchains helps firms to implement and choose the technology specific to their needs. Except for Foodchain, all firms we studied were leaning to implement a hybrid blockchain solution, due to its flexible modular architecture and enhanced security that includes permissioning. Backend modularity of blockchain systems saves the cost of entirely replacing the existing supply chain, so that the new system can be incorporated on top of and together with the existing supply chain itself. Finally, due to their high data accuracy, companies such as Provenance that traced tuna fish and Ripe.io that traced tomatoes were benefitted far more by blockchain-based traceability systems compared with traditional pre-blockchain systems. Information related to an individual tuna fish or single tomato, rather than merely being faced with information about the whole batch it was in, or having to deal with another unit, was obtained rapidly, making more efficient the tracing of its origin.

\section{Discussion and Conclusion}

This article aimed at contributing to the field of supply chain management innovation by investigating the benefits of blockchain-based traceability in food supply chains. While blockchain technology has begun to demonstrate how it can transform industries and enhance business model innovation (Zhao et al., 2016; Tandon et al., 2021), it also constitutes a managerial challenge for incumbents (Beck \& Muller-Bloch, 2017). To more fully leverage the potential of blockchain technology, engagement is needed throughout the supply chain. Blockchain-based traceability provides value only if all supply chain partners adopt and actively contribute to it (Gurtu \& Johny, 2019). Thus, adoption of blockchain technology may be hindered by various issues involving usage by personnel, technical aspects, education, policies, and local regulatory frameworks (Kamilaris et al., 2019).

\section{Contribution to theory}

One of the overall findings of our study was that research involving blockchain-based applications in supply chain management is still emerging. There is a growing need for more scholarly studies on the topic. Also, common practices in blockchain-enabled food traceability systems have often not yet been operationalized, as companies are still experimenting and implementing what they have been learning from individual pilot projects. That said, our results contribute to the widening body of literature on blockchain-based traceability in several ways. In particular, the traceability elements identified by Opara (2003) provided a feasible framework to analyze cases of firms experimenting with blockchain-based traceability in the food supply chain context. However, our findings go further, for example noting the traceability of allergens, which was not discussed in Opara's (2003) framework, likewise recognizing that blockchain enables a more detailed approach to data traceability than was previously possible.

Traceability is important in preventing and responding to food crises such as food contamination. We agree with Dabbene et al. (2014) that blockchain-based solutions can be used effectively for food traceability because of their ability to better address length, depth, and precision in supply chains. Internal traceability attributes such as lot number, pack date, and order number, which have already been used, can now be recorded on a blockchain digitally and dynamically at each stage of the food supply chain. On the other hand, blockchain solves a social problem, in addition to a technical problem (Kamath, 2018). We agree with Azzi et al. (2019), Gurtu and Johny (2019) and Behnke and Janssen (2020) that by adopting blockchain technology, firms can create more reliable, transparent, and secure traceability systems, which contributes to food safety and quality, and thus to consumer trust, provided that all food supply chain entities contribute to the system.

The results also confirm that a hybrid blockchain may provide robustness and cost-savings in traceability due to its modularity benefits (Tapscott \& Tapscott, 2017). Such a system will not require replacing or reconstructing the entire supply chain, but rather allows for leveraging already available technology such as QR 


\title{
An Exploration of Blockchain-based Traceability in Food Supply Chains: On the Benefits of Distributed Digital Records from Farm to Fork
}

\author{
Mika Westerlund, Soham Nene, Seppo Leminen, Mervi Rajahonka
}

codes (Yoo \& Won, 2018). This will bring value to food businesses that do not have to face the unbearable costs of reconstructing their whole supply chain to accommodate a new technology that is supposed to save them time and money. Given the successful implementation of a blockchain-based traceability system, food supply chain entities can rapidly and accurately record, authenticate, and ensure the status of an individual food product, tracking its movement and quality throughout the product lifecycle. We argue that such as system can provide benefits to all stakeholders in a food supply chain, by helping them to produce and gain more detailed data analysis reports.

\section{Implications to practice}

This study also provides managers in the food industry with some recommendations. First, blockchain technology is increasingly demonstrating its potential for providing greater transparency, veracity, and trust in food traceability. With it involved, supply chain partners can act immediately if problems such as food scandals appear. We therefore encourage managers in food companies to experiment with blockchain technology as potentially a way to gain competitive advantage, better comply with regulations, and respond to rising consumer concerns surrounding food safety and quality.

Second, building and managing a blockchain-based food traceability system should be done in collaboration with governments to meet international compliance standards and cultivate societal knowledge about food safety. Such a system for any society will attempt to solve the problem of documentation and compliance with local and global regulatory systems involving food supply chains. This can be achieved by recording supply chain-relevant government data such as standards, regulatory guidelines, and corporate registries on a permissioned public blockchain, and comparing them with data and metadata from each supply chain transaction. This would provide secure and trustable compliance for government agencies related to food supply, agriculture, health, infrastructure, natural resources, economy, employment, and others.

Third, experimenting with food-oriented blockchain pilots may result in companies seeking to implement the system more broadly for their food supply chains. While Behnke and Janssen (2020) list scalability as one of technical hindrances for blockchain systems, they also argue that current blockchain-based food traceability pilots indicate that scaling can, and indeed will eventually be reached. We therefore suggest that leveraging blockchain technology can help companies that deal with food to identify vulnerabilities in their current food supply chains. This would allow managers of food businesses to better gain the trust of people in regard to their food products, as those vulnerabilities are reduced or removed through a distributed ledger system. Thus, food brand managers should start building stories about their respective brands that engage all supply chain entities, and which can be supported by real-time information obtained from their food supply chain through a blockchain-based traceability system.

\section{Limitations and future research avenues}

Limitations to our study are at least two-fold. First, blockchain-based applications are still emerging in the market. We were only able to explore five cases in a specific area of food traceability involving supply chains. Further, each of those cases is recent or involved still in ongoing experimentations. Thus, this paper provided insights on the early experiences and evidence available at the current time involving blockchains in food supply chains. Thus, future research would benefit from analyzing a larger number of cases and focusing on more mature blockchain-based solutions. In particular, the link between blockchain-based tracing and specific broader social sustainability benefits for food should be examined, as also suggested in other recent studies (Paliwal et al., 2020; Lim et al., 2021; Vu et al., 2021).

Second, our case analyses were based on publicly available data, such as academic and practitioneroriented articles, reports, news, blogs, and corporate websites. Future research would benefit from first-hand investigation of blockchain-based companies currently conducting food traceability system experiments and risk management practices (see Shahbazi \& Byun, 2021), as well as exploring the various perceptions currently held about the benefits of blockchain by supply chain entities at different stages from farm to fork. This could be done either through interviews and surveys of various targeted stakeholders, or through action research by scholars participating in designing solution architecture for blockchain-based traceability systems. 


\title{
An Exploration of Blockchain-based Traceability in Food Supply Chains: On the Benefits of Distributed Digital Records from Farm to Fork
}

\author{
Mika Westerlund, Soham Nene, Seppo Leminen, Mervi Rajahonka
}

\section{Acknowledgments}

A previous version of this paper was presented at the ISPIM Connects Ottawa Conference from April 7-10th, 2019. Also, Professor Seppo Leminen warmly acknowledges the funding from Drammen City Municipality for his chaired professorship of Innovation and Entrepreneurship, which enabled completing his part in the article.

\section{References}

Apte, S., \& Petrovsky, N. 2016. Will blockchain technology revolutionize excipient supply chain management? Journal of Excipients and Food Chemicals, 7(3), 910.

Astill, J., Dara, R.A., Campbell, M., Farber, J. M., Fraser, E. D. G., Sharif, S., \& Yada, R. Y. 2019. Transparency in food supply chains: A review of enabling technology solutions. Trends in Food Science \& Technology, 91: 240-247.

DOI: https://doi.org/10.1016/j.tifs.2019.07.024

Aung, M.M., \& Chang, Y.S. 2014. Traceability in a food supply chain: Safety and quality perspectives. Food Control, $\quad 39$ : 172-184. DOI: https://doi.org/10.1016/j.foodcont.2013.11.007

Azzi, R., Chamoun, R.K., \& Sokhn, M. 2019. The power of a blockchain-based supply chain. Computers \& Industrial Engineering, 135: 582-592. DOI: https://doi.org/10.1016/j.cie.2019.06.042

Beck, R., \& Müller-Bloch, C. 2017. Blockchain as Radical Innovation: A Framework for Engaging with Distributed Ledgers. Proceedings of the 50th Hawaii International Conference on System Sciences. 53905399.

http://hdl.handle.net/10125/41815

Behnke, K., \& Janssen, M.F W.H.A. 2020. Boundary conditions for traceability in food supply chains using blockchain technology. International Journal of Information Management, 52, 101969. DOI: https://doi.org/10.1016/j.ijinfomgt.2019.05.025

Bhatt, T., Buckley, G., McEntire, J.C., Lothian, P., Sterling, B., \& Hickey, C. 2013. Making Traceability Work across the Entire Food Supply Chain. Journal of Food Science, 78(S2): DOI: https://doi.org/10.1111/1750-3841.12278

Bumblauskas, D., Mann, A., Dugan, B., \& Rittmer, J. 2020. A blockchain use case in food distribution: Do you know where your food has been? International Journal of Information Management, 52, 102008. DOI: https://doi.org/10.1016/j.ijinfomgt.2019.09.004
Casado-Vara, R., Prieto, J., De la Prieta, F., \& Corchado, J. M. 2018. How blockchain improves the supply chain: Case study alimentary supply chain. Procedia Computer Science, 134: 393-398.

DOI: https://doi.org/10.1016/j.procs.2018.07.193

Casino, F., Dasaklis, T.K., \& Patsakis, C. 2019. A systematic literature review of blockchain-based applications: Current status, classification and open issues. Telematics and Informatics, 36: 55-81.

DOI: https://doi.org/10.1016/j.tele.2018.11.006

Casino, F., Kanakaris, V., Dasaklis, T.K., Moschuris, S., Stachtiaris, S., Pagoni, M., \& Rachaniotis, N.P. 2020. Blockchain-based food supply chain traceability: a case study in the dairy sector. International Journal of Production Research, DOI: https://doi.org/10.1080/00207543.2020.1789238

Chang, S.E., \& Chen, Y. 2020. When Blockchain Meets Supply Chain: A Systematic Literature Review on Current Development and Potential Applications. IEEE Access, 8: 62478-62494.

DOI: https://doi.org/10.1109/ACCESS.2020.2983601

Chen, R.-Y. 2015. Autonomous tracing system for backward design in food supply chain. Food Control, 51: 70-84.

DOI: https://doi.org/10.1016/j.foodcont.2014.11.004

Chen, H., Chen, Z., Lin, F., \& Zhuang, P. 2021. Effective Management for Blockchain-Based Agri-Food Supply Chains Using Deep Reinforcement Learning. IEEE Access, 9: 36008-36018, DOI: https://doi.org/10.1109/ACCESS.2021.3062410

Dabbene, F., Gay, P., \& Tortia, C. 2014. Traceability issues in food supply chain management: A review. Biosystems Engineering, 120: 65-80.

DOI:

https://doi.org/10.1016/j.biosystemseng.2013.09.006

Ene, C. 2013. The Relevance of Traceability in the Food Chain. Economics of Agriculture, 2/2013: 287-297.

DOI: https://doi.org/10.22004/ag.econ.152808

Etemadi, N., Borbon-Galvez, Y., Strozzi, F., Etemadi, T. 2021. Supply Chain Disruption Risk Management with Blockchain: A Dynamic Literature Review. Information, 12, 70 .

DOI: https://doi.org/10.3390/infol2020070

Garaus, M., \& Treiblmaier, H. 2021. The influence of blockchain-based food traceability on retailer choice: The mediating role of trust. Food Control, 129, 108082.

DOI: https://doi.org/10.1016/j.foodcont.2021.108082

Grecuccio, J., Giusto, E., Fiori, F., \& Rebaudengo, M. 2020. Combining Blockchain and IoT: Food-Chain Traceability and Beyond. Energies, 13(15), 3820.

DOI: https://doi.org/10.3390/en13153820 


\section{An Exploration of Blockchain-based Traceability in Food Supply Chains: On the Benefits of Distributed Digital Records from Farm to Fork}

\section{Mika Westerlund, Soham Nene, Seppo Leminen, Mervi Rajahonka}

Gurtu, A., \& Johny, J. 2019. Potential of blockchain technology in supply chain management: a literature review. International Journal of Physical Distribution \& Logistics Management, 49(9): 881-900.

DOI: https://doi.org/10.1108/IJPDLM-11-2018-0371

He, Y., Huang, H., Li, D., Shi, C. \& Wu, S.J. 2018. Quality and Operations Management in Food Supply Chains: A Literature Review. Journal of Food Quality, 2018, 7279491.

https://doi.org/10.1155/2018/7279491

Iansiti, M., \& Lakhani, K.R. 2017. The truth about blockchain. Harvard Business Review, 95(1): 118-127.

Kamath, R. 2018. Food Traceability on Blockchain: Walmart's Pork and Mango Pilots with IBM. The JBBA, 1(1), 3712.

DOI: https://doi.org/10.31585/jbba-1-1-(10)2018

Kamilaris, A., Fonts, A., \& Prenafeta-Boldú, F.-X. 2019. The rise of blockchain technology in agriculture and food supply chains. Trends in Food Science \& Technology, 91: 640-652.

DOI: https://doi.org/10.1016/j.tifs.2019.07.034

Kayikci, Y., Subramanian, N., Dora, M., \& Bhatia, M.S. 2020. Food supply chain in the era of Industry 4.0: blockchain technology implementation opportunities and impediments from the perspective of people, process, performance, and technology. Production Planning \& Control,

DOI: https://doi.org/10.1080/09537287.2020.1810757

Kim, H.M., \& Laskowski, M. 2017. Agriculture on the Blockchain: Sustainable Solutions for Food, Farmers, and Financing. In Tapscott, D. (Ed.)(2018). Supply Chain Revolution, Barrow Books.

DOI: http://dx.doi.org/10.2139/ssrn.3028164

Kramer, M.P., Bitsch, L., \& Hanf, J. 2021. Blockchain and Its Impacts on Agri-Food Supply Chain Network Management. Sustainability, 13(4), 2168.

DOI: https://doi.org/10.3390/su13042168

Kshetri, N. 2018. Blockchain's roles in meeting key supply chain management objectives. International Journal of Information Management, 39: 80-89. DOI: https://doi.org/10.1016/j.ijinfomgt.2017.12.005

Kumar, J., Hallqvist, C., \& Ekwall, D. 2017. Developing a Framework for Traceability Implementation in the Textile Supply Chain. Systems, 5(2), 33.

DOI: https://doi.org/10.3390/systems5020033

Lemieux, V.L. 2016. Trusting records: is Blockchain technology the answer? Records Management Journal, 26(2): 110-139.

DOI: https://doi.org/10.1108/RMJ-12-2015-0042

Lim, M.K., Li, Y., Wang, C., \& Tseng, M.-L. 2021. A literature review of blockchain technology applications in supply chains: A comprehensive analysis of themes, methodologies and industries. Computers \& Industrial Engineering, 154, 107133. DOI: https://doi.org/10.1016/j.cie.2021.107133
Lin, X., Chang, S.-C., Chou, T.-H., Chen, S.-C., \& Ruangkanjanases, A. 2021. Consumers' Intention to Adopt Blockchain Food Traceability Technology towards Organic Food Products. International Journal of Environmental Research and Public Health, 18(3), 912.

DOI: https://doi.org/10.3390/ijerph18030912

Mansfield-Devine, S. 2017. Beyond Bitcoin: using blockchain technology to provide assurance in the commercial world. Computer Fraud \& Security, 2017(5): 14-18.

DOI: https://doi.org/10.1016/S1361-3723(17)30042-8

Min, H. 2019. Blockchain technology for enhancing supply chain resilience. Business Horizons, 62: 35-45. DOI: https://doi.org/10.1016/j.bushor.2018.08.012

Moe, T. 1998. Perspectives on traceability in food manufacture. Trends in Food Science and Technology, 9: 211-214.

DOI: https://doi.org/10.1016/S0924-2244(98)00037-5

Mukri, B. 2018. Blockchain Technology in Supply Chain Management: A Review. International Research Journal of Engineering and Technology, 5(6): 24972500.

Müßigmann, M., von der Gracht, H., \& Hartmann, E. 2020. Blockchain Technology in Logistics and Supply Chain Management - A Bibliometric Literature Review From 2016 to January 2020. IEEE Transactions on Engineering Management, 67(4): 988-1007. DOI: https://doi.org/10.1109/TEM.2020.2980733

Opara, L.U. 2003. Traceability in agriculture and food supply chain: a review of basic concepts, technological implications, and future prospects. Journal of Food Agriculture and Environment, 1: 101106.

Paliwal, V., Chandra, S., \& Sharma, S. 2020. Blockchain Technology for Sustainable Supply Chain Management: A Systematic Literature Review and a Classification Framework. Sustainability, 12(18), 7638.

DOI: https://doi.org/10.3390/su12187638

Pearson, S., May, D., Leontidis, G., Swainson, M., Brewer, S., Bidaut, L., Frey, J.G., Parr, G., Maull, R., \& Zisman, A. 2019. Are Distributed Ledger Technologies the panacea for food traceability? Global Food Security, 20: 145-149.

DOI: https://doi.org/10.1016/j.gfs.2019.02.002

Pournader, M., Shi, Y., Seuring, S., \& Koh, S.C.L. 2020. Blockchain applications in supply chains, transport and logistics: a systematic review of the literature. International Journal of Production Research, 58(7): 2063-2081.

DOI: https://doi.org/10.1080/00207543.2019.1650976

Sarpong, S. 2014. Traceability and supply chain complexity: confronting the issues and concerns. European Business Review, 26(3): 271-284.

DOI; https://doi.org/10.1108/EBR-09-2013-0113 


\title{
An Exploration of Blockchain-based Traceability in Food Supply Chains: On the Benefits of Distributed Digital Records from Farm to Fork
}

\author{
Mika Westerlund, Soham Nene, Seppo Leminen, Mervi Rajahonka
}

Shahbazi, Z., \& Byun, Y.-C. 2021. A Procedure for Tracing Supply Chains for Perishable Food Based on Blockchain, Machine Learning and Fuzzy Logic. Electronics, 10(1), 41.

DOI: https://doi.org/10.3390/electronics10010041

Tandon, A., Kaur, P., Mäntymäki, M., \& Dhir, A. 2021. Blockchain applications in management: A bibliometric analysis and literature review. Technological Forecasting and Social Change, 166, 120649.

DOI: https://doi.org/10.1016/j.techfore.2021.120649

Tapscott, D., \& Tapscott, A. 2017. How Blockchain Will Change Organizations. MIT Sloan Management Review, 58(2): 10-13.

Tayal, A., Solanki, A., Kondal, R., Nayyar, A., Tanwar, S., \& Kumar, N. 2021. Blockchain-based efficient communication for food supply chain industry: Transparency and traceability analysis for sustainable business. International Journal of Communication Systems, 34(4), e4696.

DOI: https://doi.org/10.1002/dac.4696

Teodorescu, M., \& Korchagina, E. 2021. Applying Blockchain in the Modern Supply Chain Management: Its Implication on Open Innovation. Journal of Open Innovation: Technology, Market, and Complexity, 7(1), 80.

DOI: https://doi.org/10.3390/joitmc7010080

Treiblmaier, H. 2018. The impact of the blockchain on the supply chain: a theory-based research framework and a call for action. Supply Chain Management, 23(6): 545-559.

DOI: https://doi.org/10.1108/SCM-01-2018-0029

van Hilten, M., Ongena, G., \& Ravesteijn, P. 2020. Blockchain for Organic Food Traceability: Case Studies on Drivers and Challenges. Frontiers in Blockchain, 3, 567175.

DOI: https://doi.org/10.3389/fbloc.2020.567175

Vu, N., Ghadge, A., \& Bourlakis, M. 2021. Blockchain adoption in food supply chains: a review and implementation framework. Production Planning \& Control,

DOI: https://doi.org/10.1080/09537287.2021.1939902

Wang, Y., Han, J.H., \& Beynon-Davies, P. 2019. Understanding blockchain technology for future supply chains: a systematic literature review and research agenda. Supply Chain Management, 24(1): 62-84.

DOI: https://doi.org/10.1108/SCM-03-2018-0148

Wang, M., Wu, Y., Chen, B., \& Evans, M. 2020. Blockchain and Supply Chain Management: A New Paradigm for Supply Chain Integration and Collaboration. Operations and Supply Chain Management, 14(1): 111-122.

DOI: http://doi.org/10.31387/oscm0440290
Xiong, H., Dalhaus, T., Wang, P., \& Huang, J. 2020. Blockchain Technology for Agriculture: Applications and Rationale. Frontiers in Blockchain, 3, 7. DOI: https://doi.org/10.3389/fbloc.2020.00007

Ying, W., Jia, S., \& Du, W. 2018. Digital enablement of blockchain: Evidence from HNA group. International Journal of Information Management, 39: 1-4. DOI: https://doi.org/10.1016/j.ijinfomgt.2017.10.004

Yoo, M., \& Won, Y. 2018. A Study on the Transparent Price Tracing System in Supply Chain Management Based on Blockchain. Sustainability, 10, 4037. DOI: https://doi.org/10.3390/su10114037

Zhao, L.J., Fan, S., \& Yan, J. 2016. Overview of business innovations and research opportunities in blockchain and introduction to the special issue, Financial Innovation, 2, 28.

DOI: https://doi.org/10.1186/s40854-016-0049-2

\section{About the Authors}

Mika Westerlund, DSc (Econ), is an Associate Professor at Carleton University in Ottawa, Canada. He previously held positions as a Postdoctoral Scholar in the Haas School of Business at the University of California Berkeley and in the School of Economics at Aalto University in Helsinki, Finland. Mika earned his doctoral degree in Marketing from the Helsinki School of Economics in Finland. His research interests include open and user innovation, the Internet of Things, business strategy, and management models in high-tech and serviceintensive industries.

Soham Nene is a Business Systems Analyst with Universities Canada in Ottawa, Ontario since August 2019. He works on designing student scholarship software / system solutions by performing requirements analysis, developing software system workflows, and studying system capabilities. He holds a master's degree in the Technology Innovation Management program at Carleton University and holds an undergraduate degree in Information Technology from Pune University, India. He is passionate about technology and food innovation and entrepreneurship. While pursuing master's degree Soham worked on 'Benefits of Blockchain-based Traceability in Food Supply Chains' as his research project. 


\title{
An Exploration of Blockchain-based Traceability in Food Supply Chains: On the Benefits of Distributed Digital Records from Farm to Fork
}

\author{
Mika Westerlund, Soham Nene, Seppo Leminen, Mervi Rajahonka
}

Seppo Leminen is Drammen City Municipality chaired (Full) Professor of Innovation and Entrepreneurship in the USN School of Business at the University of South-Eastern Norway in Norway, an Adjunct Professor of Business Development at Aalto University in Finland and an Adjunct Research Professor at Carleton University in Canada. He holds a doctoral degree in Marketing from the Hanken School of Economics and a doctoral degree in Industrial Engineering and Management in the School of Science at Aalto University. $\mathrm{He}$ is an Associate Editor in Techovation and an Associate editor in BRQ, Business Research Quarterly. His current research topics includes digital business models and ecosystems (cf. Internet of Things), robotics, block chains, living labs, innovation ecosystems, collaborative and networked models of innovations, collaborative methods of innovations, as well as management and marketing models for different types of companies. Results from his research have been reported in Industrial Marketing Management, the Journal of Cleaner Production, the Journal of Engineering and Technology Management, the Journal of Business \& Industrial Marketing, Management Decision, the International Journal of Innovation Management, and the Technology Innovation Management Review, among many others.

Mervi Rajahonka, DSc (Econ), works as an RDI Advisor at the Small Business Center (SBC) at SouthEastern Finland University of Applied Sciences XAMK, Finland, and she is an Adjunct Research Professor at Carleton University in Ottawa, Canada. She has been working at SBC for about 10 years, participating in numerous EU-funded projects. She earned her doctoral degree in Logistics from the Department of Information and Service Economy at Aalto University School of Business in Helsinki, Finland. She also holds a Master's degree in Technology from Helsinki University of Technology and a Master's degree in Law from the University of Helsinki. Her research interests include business models, service modularity, and service innovations. Her research has been published in a number of journals in the areas of logistics, services, and operations management.
Citation: Westerlund, M., Nene, S., Leminen, S., Rajahonka, M. 2021. An Exploration of Blockchain-based Traceability in Food Supply Chains: On the Benefits of Distributed Digital Records from Farm to Fork. Technology Innovation Management Review, 11(6): 6-18.

http://doi.org/10.22215/timreview/1446

Keywords: Food safety, Food supply chain, Blockchain, Distributed ledger, Food innovation, Traceability, Supply chain management 